\title{
Quality Rivalry in an Industry Composed of Private and Public Firms under Privatization
}

\author{
Yasunori Ishii \\ Graduate School of Economics, Waseda University, Tokyo, Japan \\ Email: yishii@waseda.jp
}

How to cite this paper: Ishii, Y. (2018) Quality Rivalry in an Industry Composed of Private and Public Firms under Privatization. Open Journal of Social Sciences, 6, 29-42.

https://doi.org/10.4236/jss.2018.67003

Received: March 29, 2018

Accepted: July 10, 2018

Published: July 13, 2018

Copyright (C) 2018 by author and Scientific Research Publishing Inc. This work is licensed under the Creative Commons Attribution International License (CC BY 4.0).

http://creativecommons.org/licenses/by/4.0/

(c) (i) Open Access

\begin{abstract}
Modeling a duopoly in which a private firm and a public firm endogenously decide their product qualities and outputs under a privatization policy of a public firm by government, we analyze relationships between the privatization degree of the public firm and firms' product quality choices. For establishing a more actual model we adopt more generalized demand functions including firms' product qualities as variables. We find that a rise in the privatization degree of the public firm lowers the public firm's product quality, whilst it raises the private firm's one. We also show that the product quality of the public firm is not always inferior to that of the private firm, depending on their production and product quality technologies. Furthermore, we demonstrate that when the firms' production and product quality technologies are identical to each other, the product quality of the public firm is always superior to that of the private firm.
\end{abstract}

\section{Keywords}

Duopoly Composed of Private and Public Firms, Firms' Endogenous Quality Choices, Privatization

\section{Introduction}

Since the privatization of public firms became one of the central movements for economic reform, many articles have analyzed how such a movement has affected firms' optimal choices and social welfare in many industries composed of private and public firms. However, most of these articles have assumed that firms' product qualities are given exogenously contrary to the fact that almost of private and public firms in real industries determine their product qualities as well as outputs endogenously. Therefore, the existing articles have failed to investigate significant problems, namely, how the product qualities of private and public 
firms are determined endogenously in an industry composed of public and private firms and how the degree of privatization of a public firm affects their product quality rivalry ${ }^{1}$. Therefore, from both of practical and theoretical viewpoints, it is necessary and useful to clarify relationships between the degree of privatization of the public firm and the firms' product qualities by establishing a more generalized model in which private and public firms determine their product qualities as well as outputs endogenously.

With the privatization of the Japan Post and the Japan National Railway, both of which were big public firms in Japan, some promoters asserted that the quality of the service provided by these firms would improve after privatization. However, the reality appears to be rather different. In practice, numerous depopulated areas have lost services they had previously. Since these firms were privatized, they have been gradually removing some of their old services in order to gain bigger profits. Thus, many people have recognized that without rigorous analyses of the endogenous quality choices of private and public firms, it is rash to predict the economic results of the privatization policy on firms' product qualities.

To the best of my knowledge, Flavio Delbono, et al. (1996) [1] and Koji Ishibashi and Toyokazu Kaneko (2008) [2] are the only articles that analyze firms' endogenous quality choices in an industry composed of private and public firms ${ }^{2}$, by adopting a Hotelling-type demand function. However, as indicated by Yasunori Ishii (2013) [3] and Yasunori Ishii (2014) [4], such a demand function seems inappropriate from a theoretical point of view because of the following reasons: First, 1) it is not derived by solving consumers' utility maximization problem under their budget constraints; Second, 2) it depends on a unactual assumption that consumers choose at most one unit (either of zero or one) of a good in the competent industry. Therefore, it is necessary to replace the restrictive Hotelling-type demand function with a more generalized demand function to establish a more actual industry model.

In this article, by adopting a more generalized demand function that is derived in the next section, we first model a duopoly, in which a private firm and a public firm choose competitively their product qualities as well as outputs endogenously. Then, we examine how the firms decide their outputs and product qualities endogenously and how the government's privatization policy affects the product quality levels of the public and private firms. We also investigate whether the public firm's product quality is always inferior to that of the private firm. Furthermore, to clarify the effects of the public firm's privatization on the firms' product quality rivalry we analyze the firms' production quality choices by as-

\footnotetext{
${ }^{1}$ Although there are many articles discussing the issues related to the privatization of the public firm, most of them adopt quality-constant industry models and essentially the same as each other. Therefore, in this study we refer to only Toshihiro Matsumura (1998) [9] as a leading and representative article and omit other articles.

${ }^{2}$ In this article we don't use a technical word of a mixed industry, because such a word is quite ambiguous. Indeed, we have already had another type of industry composed of different types of firms, such as a mixed industry consisting of a private firm and a labor-managed firm as suggested by Yasunori Ishii (1986) [10], Yasunori Ishii (1990) [11] and Liu Chang and Yasunori Ishii (2014) [12].
} 
suming that their production and product quality technologies are the same each other.

We obtain some notable and interesting results that are not derived by the existing articles assuming that both product qualities of the private and public firms are exogenously constant. We find that an increase in the degree of privatization of the public firm reduces the product quality of the public firm but raises that of the private firm. We also show that the public firm's product quality is not always inferior to that of the private firm, depending on their production and product quality technologies. In particular, we demonstrate that if the firms' quality and production technologies are identical, the product quality of the public firm is always superior to that of the private firm, except for a case where the public firm is perfectly privatized ${ }^{3}$.

The rest of this article is organized as follows. In Section 2, we establish a two-stage game model of a duopoly, in which the public and private firms determine their product qualities as well as outputs endogenously. In Section 3, we analyze the firms' output decisions. In Section 4, we investigate the firms' product quality choices and the effects of a change in the privatization degree of the public firm on the product qualities of the private and public firms. Section 5 gives some concluding remarks and suggestions.

\section{Model and Assumptions}

Suppose a quality-choosing duopoly in which a public firm that maximizes a weight average of its profit $\Pi$ and social welfare $W$ competes against a private firm that maximizes its profit $\pi^{4}$. In this article, it is regarded that both public and private firms choose their product qualities as well as outputs endogenously. To examine the relationships between the privatization degree of the public firm and the firms' quality rivalry, it is supposed that the government already predetermined its privatization policy before the firms begin their decision makings. Therefore, the public and private firms take the privatization degree of the public firm as given when they decide their optimal product qualities and outputs.

In an industry where firms determine their product qualities endogenously, they need to obtain demand functions that reflect consumers' choices for different product qualities. Therefore, extending the well-known utility function $u$ adopted in some articles, e.g., Gianmarco Ottaviano, et al (2002) [5] and Kenji Fujiwara (2007) [6], so as to include firms' differentiated product qualities, we define the utility function of a representative consumer in our industry as follows:

${ }^{3}$ Our results are different from not only those suggested by Toshihiro Matsumura (1998) [9] but also those presented by Flavio Delbono, et al. (1996) [1] and Koji Ishibashi and Toyokazu Kaneko (2008) [2].

${ }^{4}$ Liu CHang and Yasunori Ishii (2014) [12] has modeled a quality-choosing duopoly composed of a labor-managed firm and a private firm in a post-communist country. However, in this article, we do not extend their model. Instead, we introduce firms' endogenous quality choices into a mixed industry model exploited by Toshihiro Matsumura (1998) [9]. For other models considering labor-managed firms and private firms, see Yasunori Ishii (1986) [10] and Yasunori Ishii (1990) [11]. 


$$
u=A(x+X)+\alpha(q x+Q X)-a\left(x^{2}+X^{2}\right) / 2-b x X+z,(b<a)
$$

where $x(X)$ and $q(Q)$ are the output and product quality of the private (public) firm, respectively, $z$ is demand for the aggregated good (say numéraire in this article), and $A, a, b$, and $\alpha$ are all positive constants.

Then, a utility maximization problem under a budget constraint leads to the following inverse demand functions of private and public firms (see Yasunori Ishii (2013) [3], Yasunori Ishii (2014) [4], and Yasunori Ishii (2017) [7] for their derivation):

$$
p=A+\alpha q-a x-b X, P=A+\alpha Q-a X-b x,
$$

where $p$ and $P$ are the prices of the goods supplied by the private and public firms, respectively. In (2), $b<a$ implies that the effect of a change in a firm's output on its price is larger than the cross-effect on its rival's price. If the firms' product qualities are exogenous, these inverse demand functions reduce to the traditional demand functions that include only outputs as variables ${ }^{5}$.

Since the demand functions given by (2) are derived by using a utility function defined as (1), they seem to be restrictive. However, they are the most general and realistic ones at the present stage of development of quality economics that analyzes firms' endogenous quality choices, because they eliminate the restrictive features of Hotelling-type demand functions mentioned in the previous section (see Yumiko Taba and Yasunori Ishii (2016) [8]).

Now, adopting the demand functions expressed as (2), the profits of the private and public firms are defined as

$$
\begin{gathered}
\pi=(A-a x-b X+\alpha q) x-c(x)-h(q), \\
\Pi=(A-a X-b x+\alpha Q) X-C(X)-H(Q),
\end{gathered}
$$

respectively, where $c(x)(C(X))$ is a private (public) firm's production cost function for output $x(X)$, and $h(q)(H(Q))$ is a private (public) firm's quality cost function for attaining product quality $q(Q)$.

With respect to firms' cost functions in (3.1) and (3.2), we adopt a plausible assumption that the firms' production and quality cost functions are all strictly increasing and convex: that is,

$$
\begin{gathered}
c^{\prime}(x)>0, c^{\prime \prime}(x)>0, C^{\prime}(X)>0, C^{\prime \prime}(X)>0, \\
h^{\prime}(q)>0, h^{\prime \prime}(q)>0, H^{\prime}(Q)>0 \text { and } H^{\prime \prime}(Q)>0 .
\end{gathered}
$$

However, since it is not convincing to decide definitely signs of the third derivatives of these cost functions, we regard that all their absolute values are small enough to avoid arbitrary conclusions without losing the essence of this study. Of course, these cost functions reflect firms' production and quality technologies.

On the other hand, because social welfare $W$ in this industry is the sum of the

${ }^{5}$ Under the same conditions as those in which above inverse demand functions are derived, the demand functions for the public and private firms are given by $X=\{a \alpha Q-b \alpha q-a P+b p+(a-b) A\} /\left(a^{2}-b^{2}\right)$ and $x=\{a \alpha q-b \alpha Q-a p+b P+(a-b) A\} /\left(a^{2}-b^{2}\right)$, respectively. 
consumer and producer surpluses, considering the utility function of a representative consumer defined as (1), $W$ is given by

$$
\begin{aligned}
W= & A(x+X)+\alpha(q x+Q X)-a\left(x^{2}+X^{2}\right) / 2 \\
& -b x X-c(x)-C(X)-h(q)-H(Q) .
\end{aligned}
$$

Hence, the above notation enables us to describe the specific decision problem of the economic units, as follows: the private firm decides $x$ and $q$ to maximize $\pi$, and the public firm chooses $X$ and $Q$ to maximize $Z=\lambda \Pi+(1-\lambda) W$, given the privatization degree of the public firm $\lambda$ that is implemented by the government. While the public firm is completely nationalized (privatized) when $\lambda$ is zero (unity), it is partially privatized when $\lambda$ is positive but smaller than unity.

To solve the maximization problem mentioned above, we suppose that the private and public firms play a two-stage game. In the first stage, the firms choose their product qualities, $q$ and $Q$. In the second stage, the firms decide their outputs, $x$ and $X$. This two-stage game problem is solved by backward induction in this article.

\section{Output Choices in the Second Stage}

In this section, we explore the output choices of the private and privatized public firms in the second stage. We suppose that the firms engage in Cournot quantity competition $^{6}$. Therefore, given the privatization degree $\lambda$ of the public firm predetermined by the government and the firms' product qualities, $q$ and $Q$, decided by the firms in the previous stage, the private and public firms uncooperatively choose $x$ and $X$ to maximize $\pi$ and $Z$, respectively. Therefore, the industry equilibrium conditions in the output-choosing second stage are given by

$$
\begin{gathered}
-2 a x-c^{\prime}(x)-b X+A+\alpha q=0, \\
-b x-a(1+\lambda) X-C^{\prime}(X)+A+\alpha Q=0,
\end{gathered}
$$

where (5.1) and (5.2) are the first-order conditions and reaction functions of the private and public firms, respectively.

Considering the firms' demand functions and their production and quality cost functions described in the previous section, we obtain

$$
\begin{aligned}
& \pi_{x x}=\partial^{2} \pi / \partial x^{2}=-2 a-c^{\prime \prime}(x)<0, \pi_{x X}=\partial^{2} \pi / \partial X \partial x=-b<0, \\
& Z_{X X}=\partial^{2} Z / \partial X^{2}=-\left\{a(1+\lambda)+C^{\prime \prime}(X)\right\}<0, Z_{X x}=\partial^{2} Z / \partial x \partial X=-b<0 .
\end{aligned}
$$

Therefore, both the private and public forms' second-order conditions are satisfied ( $\pi_{x x}<0, Z_{X X}<0$ ), and both their reaction curves are negatively sloped ( $\left.\mathrm{d} X / \mathrm{d} x=-\pi_{x x} / \Pi_{X x}<0, \mathrm{~d} x / \mathrm{d} X=-\Pi_{X X} / \pi_{x X}<0\right)$, which implies that their outputs are strategic substitutes for each other. Moreover, since $\pi_{x x}+Z_{X X}<0$ and $\pi_{x x} Z_{X X}-\pi_{x X} Z_{X x}>0$ hold, the industry equilibrium in this stage is stable ${ }^{7}$.

${ }^{6}$ In a two-stage game model, even if firms selected different product qualities in the first stage endogenously, they can act as Cournot quantity competitors in the second stage, given the different product qualities.

${ }^{7}$ For the partial differentiation of $\pi$ and $Z$ with respect to their variables $k$ and $K$, we use the following abbreviations such as $\pi_{k}=\partial \pi / \partial k, \pi_{k K}=\partial^{2} \pi / \partial K \partial k, Z_{K K}=\partial^{2} Z / \partial K^{2}$, and so on. 
As is obvious from (5.2), $\Pi_{X}$ and $W_{X}$ have different signs, and $W_{X}-\Pi_{X}=a X>0$ holds for $0<\lambda<1$ at the industry equilibrium. Thus, we obtain $\Pi_{X}<0<W_{X}$, which implies that the output of the public firm is larger than that maximizing its profit, but smaller than that maximizing social welfare. It follows that the public firm faces the following dilemma: when the public firm increases (decreases) its output in order to raise social welfare (profit), it reduces its profit (social welfare). This dilemma is one of the most difficult ongoing problems for public firms.

Unlike private firms, public firms are often requested by the government to increase their outputs in order to raise social economic welfare. However, such a request results in a profit reduction (or loss increase), despite the improvement in social welfare. Therefore, the public firms cannot satisfy the request to increase profit and social welfare simultaneously through adjusting their outputs, because the public firm cannot attain the conditions for maximizing its profit and social welfare at the same time.

Solving (5.1) and (5.2) simultaneously, we obtain the optimal outputs of the private and public firms in the second stage. Clearly, these equilibrium conditions show that the firms' optimal outputs are both functions of the privatization degree of the public firm and of their product qualities. Therefore, we can examine the relationships among the firms' outputs $x$ and $X$, their product qualities $q$ and $Q$, and the public firm's privatization degree $\lambda$ by using (5.1) and (5.2).

Totally differentiating the industry equilibrium conditions in the output-choosing second stage given by (5.1) and (5.2) with respect to $x, X, q, Q$ and $\lambda$, we have

$$
\left[\begin{array}{ll}
\pi_{x x} & \pi_{x X} \\
Z_{X x} & Z_{X X}
\end{array}\right]\left[\begin{array}{l}
\mathrm{d} x \\
\mathrm{~d} X
\end{array}\right]=\left[\begin{array}{c}
-\alpha \mathrm{d} q \\
-\alpha \mathrm{d} Q+a X \mathrm{~d} \lambda
\end{array}\right]
$$

Thus, from (7) we obtain the effects of changes in the firms' product qualities and the privatization degree of the public firm on the firms' optimal outputs in the second stage, given other things.

First, deriving $x_{q}, x_{Q}, X_{q}$, and $X_{Q}$ from (7), and substituting the conditions on the firms' production cost functions, (5.1), (5.2), and (6) into the results, we get the effects of changes in the firms' product qualities on the firms' outputs as follows:

$$
\begin{aligned}
& x_{q}=-\alpha Z_{X X} / D>0, \quad x_{Q}=\alpha \pi_{x X} / D<0, \\
& X_{q}=\alpha Z_{X x} / D<0, \quad X_{Q}=-\alpha \pi_{x x} / D>0 .
\end{aligned}
$$

where $D=\pi_{x x} Z_{X X}-\pi_{x X} Z_{X x}>0$ under the conditions $b<a$ and $0 \leq \lambda \leq 1$. Therefore, from (8) we present the following proposition:

Proposition 1: While a rise in the product quality of the public (private) firm increases the output of the public (private) firm, it decreases the output of the private (public) firm, and vice versa.

Next, considering $b<a$ and $0 \leq \lambda \leq 1$, we obtain the following results with respect to the effects of changes in the firms' product qualities on their outputs: 


$$
0<\left|x_{Q}\right|<X_{Q}, \quad 0<\left|X_{q}\right|<x_{q} .
$$

It follows that the optimal output of each firm responds more sensitively to a change in its own quality than it does to a change in its rival's quality. In other words, (9) confirms the well-known characteristic feature that the direct effect of a change in the product quality of each firm on its output is generally larger than the cross-effect on its rival's output. Furthermore, it is also easily shown from (9) that a rise in the product quality of every firm increases the total output of the industry, and vice versa.

On the other hand, under the conditions given by (6) and the inverse demand functions derived as (2), (7) presents the effects of a change in the privatization degree of the public firm on the optimal outputs of the public and private firms:

$$
x_{\lambda}=-\alpha \pi_{x X} / D>0, \quad X_{\lambda}=\alpha \pi_{x x} / D<0, x_{\lambda}<-X_{\lambda} .
$$

Accordingly, we paraphrase (10) as the following proposition concerning with the industry organization of a quality-choosing duopoly composed of private and public firms:

Proposition 2: Given the firms product qualities, a rise in the privatization degree of the public firm increases the output of the private firm and decreases that of the public firm, while it reduces the total output of the quality-choosing industry, and vice versa.

Clearly, Proposition 2 indicates that while an increase in the privatization of the public firm promotes the private sector nature of the public firm, it decreases the market share of the public firm, given other things. As a result, the privatization of the public firm simultaneously implies the privatization of the industry itself as a whole, which leads to a reduction in total output. Therefore, it is essential to clarify how the public firm's privatization affects the product qualities of the firms that compete in a quality-choosing industry.

\section{Quality Decisions in the First Stage}

In the first stage, the private and public firms decide their product qualities, $q$ and $Q$, to maximize $\pi$ and $Z$, respectively, given the rival's quality choice, the degree of privatization of the public firm, and other exogenous variables. Therefore, considering that the firms' outputs, $x$ and $X$, will be chosen optimally in the next stage, the industrial equilibrium in the quality-setting first stage is characterized by

$$
\begin{gathered}
\alpha b^{2} x / D-h^{\prime}(q)=0, \\
\{-\lambda b X+(1-\lambda) a x\} x_{Q}-H^{\prime}(Q)=0,
\end{gathered}
$$

where (11.1) and (11.2) are the first-order conditions and reaction functions of the private and public firms, respectively.

It is assume here that both $h^{\prime \prime}(q)$ and $H^{\prime \prime}(Q)$ are large enough to satisfy $\pi_{q q}=\alpha b^{2} x_{q} / D^{2}-h^{\prime \prime}(q)<0$ and $Z_{Q Q}=\left\{-\lambda b X_{Q}+(1-\lambda) a x_{Q}\right\} x_{Q}-H^{\prime \prime}(Q)<0$ to make both maximization problems of the private and public firms meaningful. 
Then, considering $\pi_{q Q}=\alpha b^{2} x_{q} / D^{2}<0, \quad Z_{Q q}=\left\{-\lambda b X_{q}+(1-\lambda) a x_{q}\right\} x_{Q}<0$, and (9), we ensure that both firms' second-order conditions are satisfied, and that the industry equilibrium is stable. Furthermore, $\pi_{q Q}<0$ and $Z_{Q q}<0$, together with $\pi_{q q}<0$ and $Z_{Q Q}<0$, demonstrate that the firms' product qualities are also strategic substitutes for each other. Under the above conditions, we obtain the firms' optimal product qualities by solving (11.1) and (11.2) simultaneously with respect to $q$ and $Q$. Of course, since negative product qualities are meaningless from a practical point of view, they are both regarded as positive.

\subsection{The Effects of Privatization on Firms' Product Qualities}

In this subsection, we investigate how a change in the privatization degree of the public firm affects the product qualities of the private and public firms. This is a key issue when a government privatizes its public firm. People are interested in the privatization policy for public firms because this changes simultaneously the product qualities of the private and public firms through product quality rivalry.

Totally differentiating (11.1) and (11.2) with respect to $q, Q$, and $\lambda$, and substituting (5.1), (5.2), (6), and (9) into the results, we obtain

$$
\left[\begin{array}{cc}
\pi_{q q} & \pi_{q Q} \\
Z_{Q q} & Z_{Q Q}
\end{array}\right]\left[\begin{array}{l}
q_{\lambda} \\
Q_{\lambda}
\end{array}\right]=\left[\begin{array}{c}
-\pi_{q x} x_{\lambda} \\
-Z_{Q x} x_{\lambda}-Z_{Q X} X_{\lambda}
\end{array}\right]
$$

In (12), $-\pi_{q x} x_{\lambda}=-\alpha b x_{\lambda} / D<0$ and

$-Z_{Q x} x_{\lambda}-Z_{Q X} X_{\lambda}=\alpha b\left\{a(1-\lambda) x_{\lambda}-b \lambda X_{\lambda}\right\} / D>0$ hold under the conditions of the firms' cost functions, (10), (11.1), and (11.2). Consequently, considering $\pi_{q q}<0, Z_{Q Q}<0, \pi_{q Q}<0$, and $Z_{Q q}<0$, (12) leads to

$$
\begin{gathered}
q_{\lambda}=\left\{-\pi_{q x} x_{\lambda} Z_{Q Q}+\left(Z_{Q X} x_{\lambda}+Z_{Q X} X_{\lambda}\right) \pi_{q Q}\right\} / \Delta>0, \\
Q_{\lambda}=\left\{\pi_{q x} x_{\lambda} Z_{Q q}-\left(Z_{Q X} x_{\lambda}+Z_{Q X} X_{\lambda}\right) \pi_{q q}\right\} / \Delta<0,
\end{gathered}
$$

where $\Delta=\pi_{q q} Z_{Q Q}-\pi_{q Q} Z_{Q q}>0$. Therefore, we paraphrase (13.1) and (13.2) as the following proposition:

Proposition 3: In a quality-choosing industry composed of public and private firms, while an increase in the degree of privatization of the public firm improves the product quality of the private firm, it degrades that of the public firm, and vice versa.

This proposition is very notable. In the real world it has been widely believed that the privatization policy improves the product quality of the public firm. However, Proposition 3 indicates that a rise in the privatization degree of the public firm deteriorates the product quality of the public firm, which is contrary to the above belief about the privatization policy. This contradiction seems to have come from the misunderstanding that the people take the firm's product efficiency for its product quality.

Moreover, Proposition 3 demonstrates that the privatization of the public firm leads to the simultaneous improvement and deterioration in the product qualities of the private and public firms, which appears to be contradictory at first glance. 
However, the explanation of such a phenomenon is intuitively easy. Because the privatization of the public firm increases its private nature, the public firm lowers its costly product quality to chase larger profits, while the private firm raises its product quality to compete against the privatized public firm. As a result, the privatization policy affects the degree of product differentiation between the public and private firms.

Proposition 3 is also noteworthy from a theoretical point of view, because it theoretically clarifies the rationale behind the widespread public anxiety that the privatization of Japan Post and the Japan National Railway would reduce their product quantities of unprofitable services. It also explains logically some of the economic reforms made after the privatization of these public entities. In fact, both the privatized Japan Post and Japan National Railway have curtailed their services or qualities in rural areas after their privatization.

\subsection{Privatization and Firms' Product Qualities}

\subsubsection{A General Case}

Usually, we cannot judge definitely whether the product quality of the public firm is superior to that of the private firm, because their product qualities depend on their production and quality technology levels. The former is better than the latter in some cases, while the opposite is also true in other cases.

However, considering that Proposition 3 is always true, we have only the following three cases for the relationships among the privatization degree $\lambda(\in[0,1])$ of the (privatized) public firm and the firms' product qualities, $Q$ and $q$, as are depicted in Figure $1^{8}$ :

Obviously, Figure 1 shows that the product quality of the public firm is superior (inferior) to that of the private firm in Case 1 (Cas 2), but the former is superior (inferior) to that of the latter when the privatization degree is small (large) enough in Case 3. Therefore, we cannot judge definitely whether the product quality of the public firm is superior to that of the private firm, which implies a possibility of the case where the public firm supplies a good whose quality is superior to that of the private firm. Indeed, in some industries consisting of the public and private firms, the product quality of the public firm is higher than that of the private firm in the real world ${ }^{9}$.

Furthermore, considering a common criterion that the larger (smaller) the difference between the firms' product qualities, the less (more) intense the quality competition between the public and private firms is, Figure 1 clarifies that while an increase in the privatization degree of the public firm always makes the firms quality competition more (less) intense in Case 1 (Case 2), it makes the firms' quality competition more (less) intense when the privatization degree is small (large) enough in Case 3. Hence, this result demonstrates that the effect of a change in the privatization degree of the public firm on the quality competition

${ }^{8}$ In Figure 1, it is just locational relationships between the depicted curves that we should pay attention. We can ignore their curvatures.

${ }^{9}$ In Japan, some public hospitals, universities, zoos, and insurance institutes supply higher-quality services than do their private counterparts. 



Figure 1. Case 1: If $Q$ is larger than or equal to $q$ at $\lambda=1$, then $Q$ is always larger than $q$ for $\lambda \in[0,1)$. Case 2: If $Q$ is smaller than or equal to $q$ at $\lambda=0$, then $Q$ is always smaller than $q$ for $\lambda \in(0,1]$. Case 3: If $Q$ is greater than $q$ at $\lambda=0$, but smaller than $q$ at $\lambda=1$, then $Q$ is larger than $q$ for $\lambda \in[0, \tilde{\lambda})$, but $Q$ is smaller than $q$ for $\lambda \in(\tilde{\lambda}, 1]$, where $\tilde{\lambda}$ is the privatization degree that equalizes $Q$ and $q$. 
between the public and private firms is not also judged definitely.

\subsubsection{A Equal Technological Case}

The arguments about Proposition 3 and Figure 1 presented in the previous subsection are true in general. However, it is more interesting and useful to examine what happens to the product qualities of the private and public firms when their production and quality technologies are identical to clarify characteristics of the public firm's privatization. Although Flavio Delbono, et al (1996) [1] and Koji Ishibashi and Toyokazu Kaneko (2008) [2] have analyzed whether the product quality of a public firm is better than that of a private firm only at $\lambda=0$ and $\lambda=1$, we compare the firms' product qualities for a whole range of privatization degree: $\lambda \in[0,1]$.

When the public firm is perfectly privatized under the condition that the firms' quality and production technologies are identical, it becomes the same as the private firm. Consequently, the industry reduces to a duopoly in which the two identical private firms with the same production and quality technologies compete against to maximize their profits. Thus, the product quality $Q$ of the perfectly privatized public firm is the same as that $q$ of the private firm, that is, $Q=q$ holds at $\lambda=1$. Therefore, considering this result and Proposition 3, we can depict the relationships between the firms' product qualities and the privatization degree of the public firm as two curves in Figure 2, which presents the following proposition:

Proposition 4: Suppose that the production and quality technologies of the public and private firms are identical. Then, (i) the product quality of the public firm is superior to that of the private firm, and a rise in the degree of privatization of the public firm makes the firms quality competition more intense, until it is perfectly privatized $(0 \leq \lambda<1)$, and (ii) the firms quality competition and product differentiation disappears when the public firm is completely privatized $(\lambda=1)$.

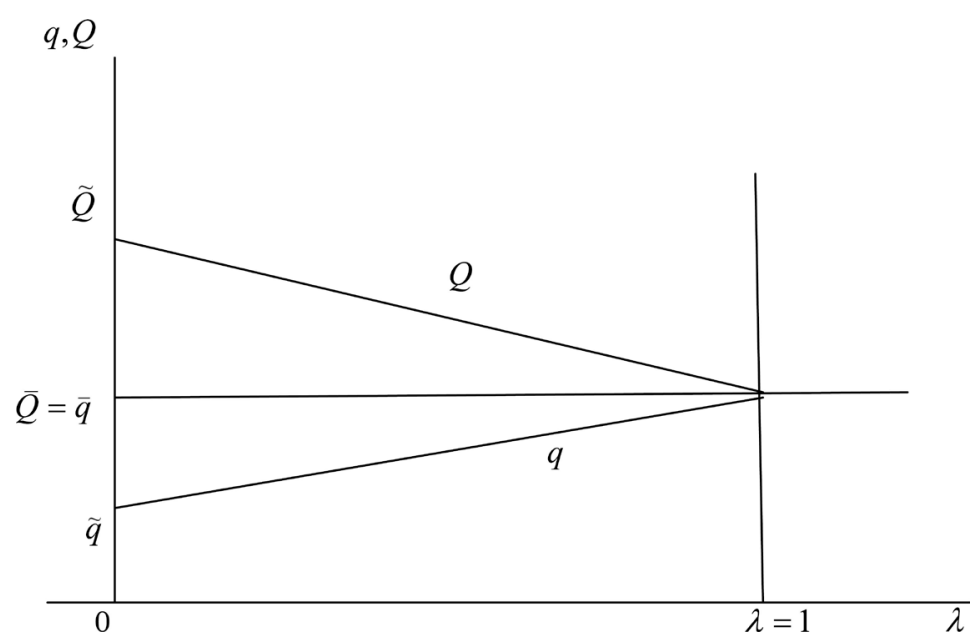

Figure 2. $\tilde{Q}(>\tilde{q})$ is the value of $Q(q)$ at $\lambda=0$, and $\bar{Q}(=\bar{q})$ is the value of $Q(q)$ at $\lambda=1$. 
According to this proposition, the public firm has an advantage over the private firm in quality competition until it is completely privatized when the production and quality technologies of the public and private firms are identical. It follows that even though the quality technology of the public firm is inferior to that of the private firm, the product quality of the public firm is also superior to that of the private firm in some ranges.

Although Proposition 4 seems to be contrary to the worldwide belief that the privatization of the public firm improves its product quality, it is not so from a theoretical point of view, because this proposition reflects the differences in the firms' objectives. While the public firm must pursue product quality to increase social welfare as large as possible under a sacrifice of its profit, the private firm acts only to maximize its profit without considering social welfare. Since product quality is necessary, but expensive for pursuing profit, the profit-maximizing private firm cannot produce a good with higher quality than that of the public firm when it possesses the same product and quality technologies as the public firm.

Of course, the deterioration of the public firm's good, owing to its privatization, is compensated to some degree by the simultaneous amelioration of the private firm's good. However, it is not certain whether such simultaneous changes in the product qualities of the public and private firms would satisfy the people having something to do with the industry. They might reject the privatization of the public firm simply because of the reduction of its product quality. Then, considering that the government aims to provide higher-quality goods so as to maximize social welfare, it is essential to consider quality changes in the public and private firms, in addition to the output and price changes, when implementing a privatization policy. Otherwise, the privatization policy for public firms in a quality-choosing industry might run contrary to its primary purpose.

\section{Concluding Remarks}

In this article, we first establish a two-stage game model of a quality-choosing duopoly composed of a private firm and a public firm that both decide their product qualities and outputs endogenously under a privatization policy of the public firm implemented by the government. Then, we investigate the relationships between the privatization degree of the public firm and the firms' optimal product qualities. To establish a realistic model, we replace the restrictive Hotelling-type demand functions used by Flavio Delbono, et al. (1996) [1] and Koji Ishibashi and Toyokazu Kaneko (2008) [2] with more general demand functions. Thus, we obtain several interesting and notable propositions that are not presented by some existing articles adopting models that assumed quality-constant mixed industries composed of private and public firms.

We find that while an increase in the privatization degree of the public firm reduces the product quality of the public firm, it raises that of the private firm, and vice versa. It follows that a rise in the degree of privatization of the public 
firm makes the quality competition between private and public firms more (less) intense in the range where the product quality of the public firm is superior (inferior) to that of the private firm, and vice versa. We also show that the product quality of the public firm is not always inferior to that of the private firm. The public firm's product quality is better than that of the private firm in some situations, and the opposite is true in other situations, depending on their production and product quality technologies. Furthermore, we demonstrate that when the production and product quality technologies of the private and public firms are identical to each other, the product quality of the public firm is always superior to that of the private firm except for the case where the public firm is perfectly privatized and becomes the same as the private firm.

The arguments in this article are also interesting and worthy in the development of economics on an industry composed of private and public firms. The phenomenon that the private and public firms determine endogenously their product qualities is very common in many real industries consisting of the private and public firms. Then, it is essentially necessary and important to investigate the endogenous choices of product qualities by the private and public firms when analyzing industries composed of those firms. Obviously, most of the existing quality-constant mixed industry models exploited initially by Toshihiro Matsumura (1998) [9] are not appropriate to examine many issues observed in such industries, whilst the quality-choosing industry model as explored in this article is suitable to investigate economic problems in such industries.

Our industry model is extended in several research directions. We can establish a model where the government decides endogenously the optimal privatization degree of the public firm in addition to the firms' endogenous quality choices. Further, we can consider a model where the government implements the optimal quality policy under the firms' endogenous quality choices ${ }^{10}$. It might be also interesting and useful to reexamine the product quality choices of private and public firms in a Bertrand model setting. Moreover, it might be meaningful to consider other types of the public firms whose objectives are different from the maximization of the positive linear combination of its profit and social welfare $^{11}$.

\section{References}

[1] Delbono, F., Denicolo, V. and Scarpa, C. (1996) Quality Choice in a Vertically Differentiated Mixed Duopoly. Economic Notes, 25, 33-46.

[2] Ishibashi, K. and Kaneko, T. (2008) Partial Privatization in Mixed Oligopoly with Price and Quality Competition. Journal of Economics, 95, 213-231.

\footnotetext{
${ }^{10}$ As regards the optimal quality policies in a duopoly composed of private and state firms that decide endogenously their product qualities as well as outputs, see Yasunori Ishii (2018) [13].

${ }^{11}$ Liu Chang and Yasunori Ishii (2014) [12] has exploited a model of a mixed industry composed of a private firm and a labor-managed firm firms. Moreover, we can consider a mixed industry where when the private firms produce only the good conveying the biggest profit, the public firm acts as a compensation pendulum for the unbalanced supply of product qualities in a society by supplying a quite different quality of good.
} 
https://doi.org/10.1007/s00712-008-0020-4

[3] Ishii, Y. (2013) On the State Advertising Policy under Quality Information Bias. Review of Development Economics, 17, 571-583. https://doi.org/10.1111/rode.12051

[4] Ishii, Y. (2014) Quality-Price Competition and Product R\&D Investment Policies in Developing and Developed Countries. Economic Record, 90, 197-206. https://doi.org/10.1111/1475-4932.12076

[5] Ottaviano, G., Tabuch, T. and Thisse, J.-F. (2002) Agglomeration and Trade Revised. International Economic Review, 43, 409-436. https://doi.org/10.1111/1468-2354.t01-1-00021

[6] Fujiwara, K. (2007) Partial Privatization in a Differentiated Mixed Oligopoly. Journal of Economics, 92, 51-65. https://doi.org/10.1007/s00712-007-0267-1

[7] Ishii, Y. (2017) International Asymmetric R\&D Rivalry and Industrial Strategy. Journal of Economics, 122, 267-276. https://doi.org/10.1007/s00712-017-0548-2

[8] Taba, Y. and Ishii, Y. (2016) Product R\&D Investment Policies in an International Duopoly. Review of Development Economics, 20, 574-582. https://doi.org/10.1111/rode.12241

[9] Matsumura, T. (1998) Partial Privatization in Mixed Duopoly. Journal of Public Economy, 70, 473-483. https://doi.org/10.1016/S0047-2727(98)00051-6

[10] Ishii, Y. (1986) On the Theory of International Trade between Capitalist and Labor-Managed Countries. Economics Letters, 21, 195-198. https://doi.org/10.1016/0165-1765(86)90064-9

[11] Ishii, Y. (1990) On the Theory of East-West Trade under Uncertainty. Journal of Economics, 52, 267-283. https://doi.org/10.1007/BF01227525

[12] Chang, L. and Ishii, Y. (2014) Privatization and Employment in Post-Communist Countries. Theoretical Economics Letters, 4, 579-583. https://doi.org/10.4236/tel.2014.47073

[13] Ishii, Y. (2018) Product R\&D Rivalry and Quality Policy in an International Industry Composed of Firms from Capitalist and Post-Communist Countries, Open Journal of Political Science, Forthcoming. 